Andrews University

Digital Commons @ Andrews University

Faculty Publications

3-1-2004

\title{
An Assessment of HIV/AIDS Risk in Higher Education Students in Yerevan, Armenia
}

Talin Babikian

Loma Linda University

Mary Catherin Freier

Loma Linda University

Gary L. Hopkins

Andrews University, ghopipad@gmail.com

Ralph DiClemente

Emory University

Duane C. McBride

Andrews University, mcbride@andrews.edu

See next page for additional authors

Follow this and additional works at: https://digitalcommons.andrews.edu/pubs

Part of the International Public Health Commons

\section{Recommended Citation}

Babikian, Talin; Freier, Mary Catherin; Hopkins, Gary L.; DiClemente, Ralph; McBride, Duane C.; and Riggs, Matt, "An Assessment of HIV/AIDS Risk in Higher Education Students in Yerevan, Armenia" (2004). Faculty Publications. 2043.

https://digitalcommons.andrews.edu/pubs/2043

This Article is brought to you for free and open access by Digital Commons @ Andrews University. It has been accepted for inclusion in Faculty Publications by an authorized administrator of Digital Commons @ Andrews University. For more information, please contact repository@andrews.edu. 


\section{Authors}

Talin Babikian, Mary Catherin Freier, Gary L. Hopkins, Ralph DiClemente, Duane C. McBride, and Matt Riggs 


\title{
An Assessment of HIVIAIDS Risk in Higher Education Students in Yerevan, Armenia
}

\author{
Talin Babikian, ${ }^{1,6}$ Mary-Catherin Freier, ${ }^{1,2}$ Gary L. Hopkins, ${ }^{2,3}$ Ralph DiClemente, ${ }^{4}$ \\ Duane McBride, ${ }^{2,5}$ and Matt Riggs ${ }^{1}$
}

\begin{abstract}
Received Feb. 28, 2002; revised May 22, 2003; accepted Sep. 22, 2003
Armenia's current sociopolitical and economic instability and the alarming HIV incidence rates in neighboring countries amplify its risk for a national epidemic. The goals of this study were to assess HIV/AIDS knowledge and risk behaviors among higher education students in Yerevan. Knowledge of HIV transmission through sexual intercourse was markedly higher than that on intravenous transmission and prevailing myths; however, HIV/AIDS knowledge was not related to risk behaviors. Tobacco and alcohol prevalence was relatively high. Students reported risky sexual behaviors, including inconsistent condom use, casual sex, and multiple partners. In addition to descriptive statistics delineating gender differences across the target behavioral domains, bivariate and multivariate statistical analyses were used to understand factors that contributed to increased risk, including early age of initiation and the relationship between substance use and risky sexual activity. The study results provide much-needed information for the development of school- and community-based AIDS prevention programs in Armenia.
\end{abstract}

KEY WORDS: Armenia; HIV/AIDS; students; health risk behaviors; youth.

\section{INTRODUCTION}

Without a cure in now its third decade, AIDS is a cause of concern for both medical and social science researchers and clinicians. More than half of all new HIV infections worldwide occur in 15- to 24-year-olds (UNAIDS/WHO, 2000). Members of this age group feel less susceptible to adverse outcomes associated with risk behaviors and are therefore at greater risk

\footnotetext{
${ }^{1}$ Department of Psychology, Loma Linda University, Loma Linda, California.

${ }^{2}$ Institute for the Prevention of Addictions, Andrews University, Berrien Springs, Michigan.

${ }^{3}$ School of Public Health, Loma Linda University, Loma Linda, California.

${ }^{4}$ Department of Behavioral Sciences and Health Education, Emory University, Atlanta, Georgia.

${ }^{5}$ Department of Behavioral Sciences, Andrews University, Berrien Springs, Michigan.

${ }^{6}$ Correspondence should be directed to Talin Babikian, Loma Linda University, Department of Psychology, 11130 Anderson St., Loma Linda, California 92350 (e-mail: tbabikian06g@univ.llu.edu).
}

for HIV/AIDS because they engage in unprotected sex, sex with multiple partners, IV drug use, and alcohol abuse. Furthermore, high-risk behaviors established in youth often extend into adulthood, making intervention at a younger age imperative to prevent chronic risk behaviors (Carasso, 1998). This study is designed to investigate aspects of HIV/AIDS risk, including HIV/AIDS knowledge base, frequency and age of initiation of target behaviors (i.e, tobacco, alcohol, and drug use and sexual activity), and predictors of HIV/AIDS risk behaviors among youth attending higher education institutes in Armenia.

\section{HIV/AIDS in Armenia}

Although the AIDS epidemic in Africa and Asia has been well documented, less attention has focused on Eastern Europe, as it was spared from the HIV epidemic until 1994 (UNAIDS/WHO, 1998). The number of new cases in this area of the world, however, is rapidly growing (UNAIDS, 1998). In fact, the world's steepest increase in the incidence of HIV was 
recorded in the newly independent states of the former Soviet Union, where the infected population doubled between 1997 and 1999 (UNAIDS, 1999). Lack of adequate resources and economic hardships such as poverty, unemployment, and labor migration contribute to this increase and are considered significant risk factors in the spread of HIV in this region (Soros Foundation Network, 2002; UNAIDS/WHO, 2002). This is particularly the case in the states of the former Soviet Union because following its fall, the republics' economic and political stabilities quickly and drastically took a turn for the worse. Currently, there are an estimated 2500 cases of HIV/AIDS in Armenia (UNAIDS/WHO, 2002), $81.5 \%$ of which are in the 20- to 39-year age group (Ministry of Health, 2000). Considered conservative, the actual rates are estimated to be much higher because relatively few people inquire about testing and those who do are afraid of social stigmatization (Ministry of Health, 2000).

Although Armenia is a low-incidence country compared to regions where the AIDS epidemic is more mature, the sociopolitical and economic realities in Armenia resemble those of neighboring countries facing an AIDS crisis. A national epidemic in Armenia, therefore, may soon become a reality if adequate prevention measures are not taken soon. The risk of an epidemic is further amplified by the "deflation of moral values" speculated to be a result of the sudden social, political, and economic changes in Armenia (Atovmyan, 2001). The recent years have also been marked by an increase in poverty and the trafficking of drugs. There are currently between 19,000 and 23,000 registered drugs users with an HIV prevalence rate of $4.5 \%$ ( $10 \%$ of registered drug users are injecting users) (Ministry of Health, 2000).

Although HIV is more efficiently transmitted through intravenous drug use, the most frequent mode of transmission is unprotected sexual activity (Ministry of Health, 2000; UNAIDS, 1998). Various economic and psychosocial factors in Armenia contribute to the need to target sexual behaviors as a means for prevention. These factors include lack of knowledge about sexually transmitted infections (STIs) and their mode of transmission and a rise in STI rates (UNAIDS, 1998). A gradual increase in the incidence rates of STIs such as syphilis and gonorrhea may presage increasing risk for HIV infection because the patterns of these sexually transmitted diseases are often parallel (Harutyunyan et al., 1998). Approximately $32 \%$ of patients visiting dispensaries in 1998 were registered with a diagnosis of syphilis as opposed to $17.5 \%$ in 1994 (UNAIDS/WHO, 2000).
In a recent study, commercial sex work was not only revealed to be relatively common in the capital city of Yerevan, but it also was found to be a significant risk factor for the spread of the virus (Melikyan, 1999). Only about $10 \%$ of commercial sex workers in the study reported consistent condom use and most perceived themselves not to be at risk. There are approximately 7,000-8,000 female sex workers in Armenia (Ministry of Health, 2000) and the HIV prevalence in this group is estimated at $6 \%$ (UNAIDS/WHO, 2002). Fifty-two percent of the prostitutes have been diagnosed with four or five STIs and approximately half of them are under the age of 28 years (Atovmyan, 2001). In addition to commercial sex work, military conflict and labor migration are also identified factors placing countries at high risk for an HIV/AIDS epidemic. Labor migration within the former Soviet states is a common threat because $20-22 \%$ of Armenians work or live part-time in Ukraine or Russia, the two countries most affected by the AIDS epidemic in the region (UNAIDS/WHO, 2002).

\section{Youth, Substance Use, and HIV/AIDS Risk}

In addition to being a widespread and serious health problem in itself (Nagy et al., 1990), the use of substances has been linked by many researchers with risk behaviors for HIV transmission (Stinson and DeBakey, 1993). Similarities between risky sexual behaviors and substance use include risk taking, experimentation, and decision making based on short-term gratification without much consideration for long-term consequences (Hochhauser, 1989). There is a paucity of information regarding the substance use behaviors of youth in Armenia; however, a study on adolescents between 14 and 16 years of age in Yerevan suggested smoking prevalence rates of $56 \%$ in males and $21 \%$ in females (a majority of these had initiated smoking between 10 and 12 years of age) (World Health Organization, 1997). The little data that are available on substance use patterns indicate that tobacco, alcohol, and drug use are on the rise in Armenia, especially among youth (Markosyan, 2000). Interestingly, although the legal smoking age is 18 years in Armenia (National Tobacco Control Program, 2002), there is no minimum legal age limit for drinking or purchasing alcohol (International Center for Alcohol Policies, 2002).

With regard to sexual behaviors, whereas conservative attitudes regarding sexual behavior were prominent in Armenia prior to the fall of the Soviet 
Union, the post-Soviet period has been characterized by more international contact and liberalized views. Young people, however, are prematurely exposed to such views without much information regarding sexuality and sexually transmitted infections to which a comparable group of adolescents in the West are introduced at a young age (Amirkhanian et al., 2001). This change in views and behaviors of young people in Armenia is characterized by current trends such as the postponement of marriage and the liberalization of sexual behavior, including premarital sex (UNAIDS, 1998). In addition, conservative attitudes and taboos related to sex education in schools have been suggested to contribute to the spread of HIV in Armenia (Hakobian, 2001). Although the available data on high-risk populations in Armenia point to groups that are more traditionally considered to be at high risk for infection (i.e., prostitutes and injecting drug users), the mere lack of data on the prevalence of risk behaviors and HIV/AIDS knowledge of youth in Armenia warranted this investigation. For all of these reasons, the target population in this study is students attending higher education institutes in Yerevan, Armenia.

\section{Study Objectives}

Epidemiologic information and current literature indicate a pressing need to determine the state of HIV/AIDS knowledge, prevalence of risk behaviors, and prevention or intervention measures in Armenia (Ministry of Health, 2000; UNAIDS/WHO, 2000), particularly regarding youth, for whom such information is scarce at best. The immediate objectives of this study are to assess the level of HIV/AIDS knowledge and prevalence of risk behaviors, identify initiation ages of the target behaviors, and better understand the predictors of risk-taking behavior. The data gathered from this study can be an essential source of information for the design and implementation of an HIV/AIDS prevention effort designed primarily for the needs of youth in Armenia.

\section{METHODS}

\section{Subjects}

Students from five higher education institutes in Yerevan, Armenia, including the State University (faculties of Law and Social Sciences) and the Institutes of Physical Education, Medicine, Arts, and Cinema/Theatre, participated in the study $(N=412$, age range 17-21 years). Data were collected in September 2000.

\section{Materials}

The questionnaire designed for this study included demographic information, prevalence of health risk behaviors, including tobacco, alcohol, and drug use; and sexual activity. Questions addressing the prevalence of risk behaviors were derived from the Centers for Disease Control and Prevention's Youth Risk Behavior Survey (YRBS), which is used as part of the Youth Risk Behavior Surveillance System (YRBSS) (Centers for Disease Control and Prevention [CDC], 2003). In addition, a 12-item HIV/AIDS knowledge scale adapted from DiClemente et al. (1993) was also included to measure the knowledge base of the students. The questionnaire was translated into Armenian and backtranslated into English in order to maximize its cultural relevance.

\section{HIV/AIDS Knowledge Scale}

In order to assess the students' HIV/AIDS knowledge, 12 items were adapted from DiClemente et al.'s (1993) 17-item HIV/AIDS Knowledge Scale, which has a reported internal reliability of .80 and a scale median of 14 (DiClemente et al., 1993). In this study, students were asked to endorse either "true," "false," or "I do not know" responses on statements about AIDS and HIV transmission. Each correct response was recoded as 1 and each incorrect response as 0 . "I do not know" responses were recoded as incorrect. The individual knowledge scores were summed and used in the analysis, $\bar{x}=7.1(S D=2.8)$, range $=$ $0-12$. Cronbach's alpha for the AIDS knowledge scale was .77, suggesting that the intercorrelations of the items were strong enough to warrant the use of a single combined score representing AIDS knowledge. In addition, the internal consistency of this scale did not improve following the deletion of each of the scale items in separate Cronbach's alpha recalculations, justifying the use of all 12 items as a measure of HIV/AIDS knowledge.

\section{Procedures}

Prior to the implementation of this survey, the Institutional Review Board (IRB) at Loma Linda University and the American University of Armenia 
reviewed and approved the protocol, questionnaire, and consent form. After attaining approval from the Minister of Education in Armenia, 5 of the 16 state-funded higher education institutes in Yerevan were selected by the Minister of Education and the researchers. Consideration was given to accessing a diverse student population from various fields, including the arts, biological/medical sciences, social sciences, and technical schools. On this basis, the Institutes of Physical Education, Arts, Cinema/Theatre, and Medicine and two faculties (Law and Social Sciences) from the Yerevan State University were selected. The Minister of Education prepared letters addressed to the deans of each participating institute. These letters were personally delivered to the respective deans at scheduled meetings during which the basic objectives of the study and methodological issues were discussed. After all five deans agreed to participate, a convenience sample of classrooms was drawn based on the number of students in each institute (we aimed to sample approximately 5\% of the student population in each institute). This convenience sample was based on the number of students in a given classroom. For example, if we needed approximately 100 students from a given school, we targeted two classrooms that had 50 students each instead of choosing smaller classes.

Students met in their regularly scheduled classrooms on the designated data collection days, but instead of their lecture, were invited to participate in this study. After a brief description and review of the consent materials, the surveys were distributed to students who chose to participate (three students chose not to participate and were given an alternative task so as not to be discriminated). There were no institute-wide marketing strategies employed nor were any incentives offered for participation.

\section{American University of Armenia}

Measures were taken to address cultural sensitivity by having local contacts review all study-related materials and methods. The staff from the Center for Health Sciences Research (CHSR) of the American University of Armenia (AUA) served as collaborators in this study and had a key role in contacting the Ministry of Education and institute deans, resolving translation issues, and editing the final version of the questionnaire and consent forms. Both the questionnaire and consent forms were pilot tested on a group of approximately 25 students enrolled in a public health course at AUA. Their input regarding ambiguities in wording and format were taken into account before a final version of the questionnaire was prepared. A double-entry method to minimize errors was used to enter the data into an SPSS database by CHSR staff. All statistical analyses were done using SPSS 10.1.

\section{RESULTS}

\section{Demographic Variables}

A total of 442 students was surveyed. Because an overwhelming majority of the respondents were in their second or third year of study ( $96 \%)$, only these students were included in all subsequent analyses. As a result, 21 responses were excluded, yielding a final sample size of 421 . The sample distribution was the following across the five educational institutes: Physical Education $(N=108$ with $7 \%$ of the student body surveyed), Arts $(N=37,7 \%$ surveyed), Cinema/Theatre ( $N=22,5 \%$ surveyed $)$, Medicine $(N=116,3 \%$ surveyed $)$, and Yerevan State University ( $N=138,3 \%$ surveyed). The mean age of respondents was 18.3 years $(S D=0.9)$. Gender was approximately equally represented in the sample (54\% male and $46 \%$ female) and across the institutes, except in the Physical Education institute, where 90\% of the sample consisted of male students. Only 1.8\% of the students were married at the time of the survey. Approximately two-thirds of the respondents were originally from the capital city of Yerevan; the rest were from various rural regions in Armenia. Because preliminary analyses did not show statistically significant differences on key outcome variables based on the students' rural versus urban background, this variable was excluded from subsequent analyses.

\section{Descriptive Statistics: Substance Use and Sexual Activity}

Sixty-seven percent of the students reported having tried smoking at some point in the past. Kaplan-Meier survival statistics were used to derive subsequent age-of-initiation statistics due to a relatively high number of "censored" or uninitiated cases. Based on these analyses, the mean and median ages for tobacco initiation were 15.0 years $(S E=$ $0.2)$ and 15.5 years $(S E=0.2)$, respectively, with a $95 \%$ mean confidence interval in the 14.6-15.4 range (168 censored cases). Approximately one-fifth of the 
students reported having smoked regularly in the last month (20 or more days). This proportion was higher in males than in females, with one-third of all males reporting regular smoking. Of those students who reported smoking in the last month, 33\% reported smoking more than 10 cigarettes per day.

Based on Kaplan-Meier survival analyses, the mean and median age of initiation for alcohol use (excluding a few sips) were 14.6 years $(S E=0.2)$ and 15.5 years $(S E=0.1)$, respectively, with a $95 \%$ mean confidence interval in the 14.3-14.9 range (141 censored cases). Twenty-one percent of the students surveyed reported that they had never tried alcohol. Of those who had drank alcohol, $70 \%$ reported drinking once a month or less; however, $27 \%$ of these respondents reported binge drinking (five or more drinks in a row) in the last month. Although approximately twothirds of the students reported that it was "okay" for them to drink every so often, only $23 \%$ admitted to drinking when alone and $28 \%$ believed it was "okay" to occasionally get drunk.

With regard to illicit drug use, approximately $6 \%$ of the students reported having tried drugs at some point in their lives. The mean and median ages of drug use initiation based on Kaplan-Meier survival analyses were 16.6 years $(S E=0.4)$ and 17.5 years $(S E=$ 0.2 ), respectively, with a $95 \%$ mean confidence interval range of 15.9-17.4 (357 censored cases). Those who had used drugs tried it on average six times in their life. The drugs identified by the students as ones they had used were, in order of prevalence, hashish, marijuana, opium, and cocaine.

Approximately $44 \%$ of the respondents reported having been sexually active. Kaplan-Meier survival statistics indicated a mean and median age of initiation for sexual activity as 15.5 years $(S E=0.2)$ and 16.0 years $(S E=0.1)$, respectively, with a $95 \%$ mean confidence interval in the 15.1-15.9 range (225 censored cases). The average number of lifetime sexual partners for the sexually experienced group was 6.6 $(S D=9.4)$. Approximately $53 \%$ of the sexually active respondents reported engaging in casual sex (knowing partner for "no more than a few days" before engaging in sex); less than $1 \%$ of the students who responded affirmatively to "casual sex" were female. Contrary to the high rate of abortions in Armenia, namely, 1 in 2.5 pregnancies (Henshaw et al., 1999), no female students reported a pregnancy or an induced abortion. However, $6 \%$ of the male students reported having impregnated a partner and $7 \%$ reported not being sure. In addition, noteworthy gender differences were observed with regard to sexual behavior; $77 \%$ of the male students reported being sexually active compared to only $7 \%$ of the females. In addition, average number of lifetime sexual partners was $7.3(S D=9.8)$ for males and $1.2(S D=0.9)$ for females.

Table I summarizes statistics for each of the above target behaviors, including both lifetime and current behaviors, by gender. The means calculated for frequency of substance use were based on the ordinal responses to the YRBS questions. After excluding students who did not endorse the given behavior, the mean of each response option range was multiplied by the frequency of endorsements per response category. The products were summed and divided by the total number of respondents for each question. These numbers are reported as the means for each behavior. These derived means are complemented by the median responses (or the range of values corresponding to the median endorsed response) (see Table I).

When asked whether condoms would protect one from acquiring an STI, an overwhelming majority $(90 \%)$ responded affirmatively. With regard to actual behavior, however, condom use was addressed only as a method of contraception. The most popular method of contraception reported during last sexual intercourse among sexually active students was condoms (74\%); $15 \%$ of the students admitted not using any form of contraception during their last intercourse, $5 \%$ used withdrawal, $5 \%$ indicated not knowing what they used, and $1 \%$ used the rhythm method. Among the reasons for not using condoms were (1) "condoms are not necessary" (48\%), (2) "another form of birth control was used" (27\%), and (3) "condoms are not acceptable to me or to my partner" (23\%). Although poor economic conditions and difficult access to condoms are often associated with low rates of condom use in Armenia (UNAIDS/WHO, 2002), none of the sexually active students reported cost or availability of condoms as a factor in their decision to utilize them. Approximately $50 \%$ of the sexually active students reported that the use of condoms was sometimes or never associated with how well they knew their partner. Furthermore, $68 \%$ of these students reported inconsistent condom use (never, sometimes, or often) during sexual intercourse.

\section{HIV/AIDS Knowledge}

Although the students demonstrated a fairly good understanding of the risks associated with sexual activity and transmission of HIV, their knowledge was 
Table I. Summary of Behaviors by Gender

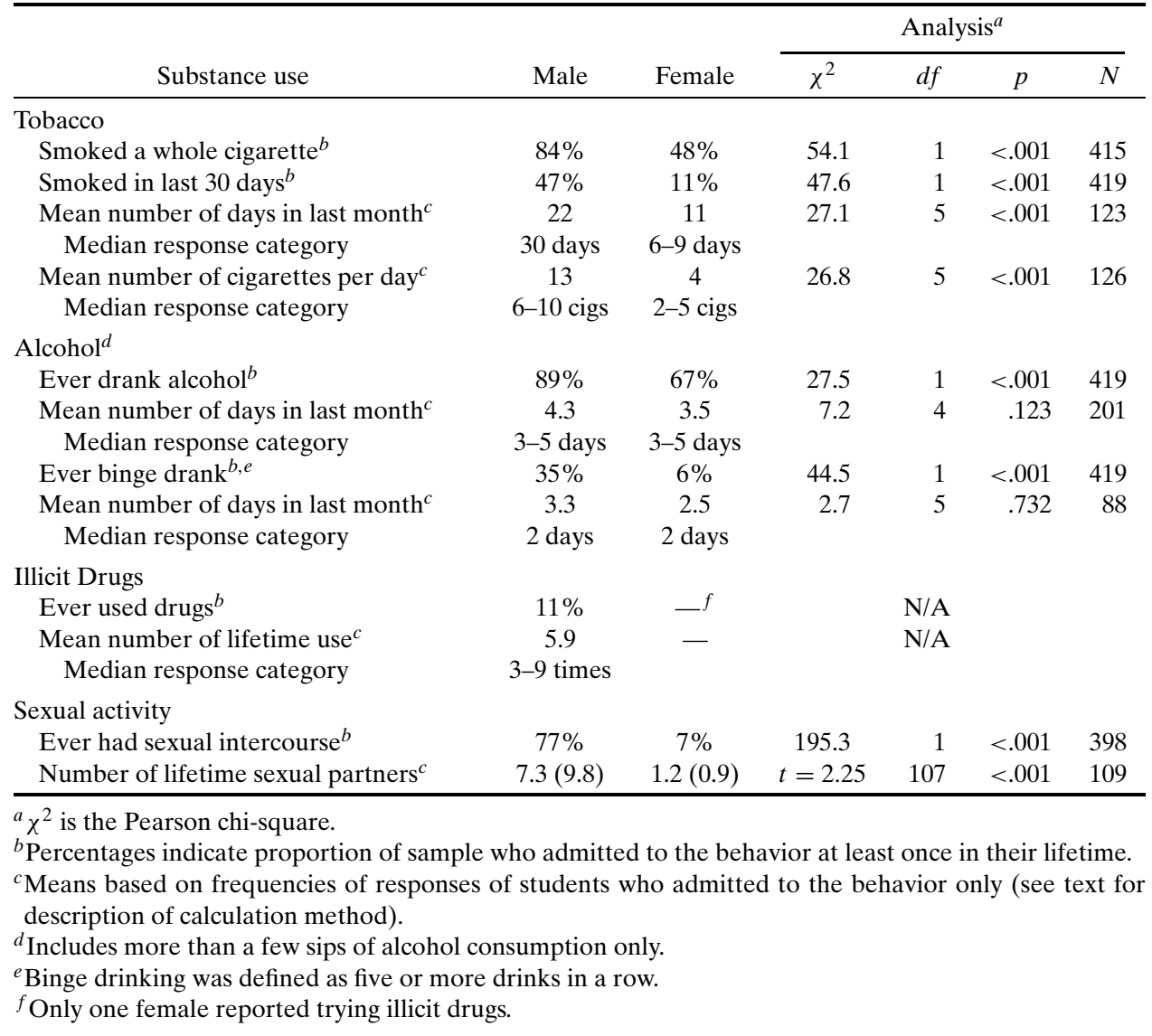

weak regarding intravenous transmission. Ninety-one percent correctly indicated that unprotected sexual activity or sexual activity with an infected partner are potential risks; however, only $49 \%$ believed that the risk of infection can be decreased by refraining from sexual activity with an injecting drug user and $32 \%$ correctly indicated that using sterile instruments during a blood test does not pose a risk for infection. Even though students were able to identify some risk factors for infection, there were still many myths reported with regard to the transmission of the virus. For instance, only $44 \%$ correctly identified that public toilets were not a risk and 70\% still believed that AIDS is a homosexual disease. In addition, $59 \%$ believed that there is a cure for AIDS (see Table II).

Students reported a variety of sources for their HIV/AIDS knowledge. The majority of the students reported some form of media, including television/radio (64\%) and books/newspapers $(50 \%)$, as their major source of information regarding HIV/AIDS. Other sources included friends (41\%), school (38\%), and parents (30\%). Only $21 \%$ and $13 \%$ of the students reported discussing HIV/AIDS with their teachers and physicians, respectively. These low proportions are expected because formal or informal classroom discussions regarding HIV and related issues are scarce at best in Armenia. In addition, the current instability in the country's health care infrastructure allows only a small minority of the Armenian population to receive adequate acute, let alone preventive, medical attention.

\section{Gender and Age of Initiation for Target Behaviors}

Kaplan-Meier survival statistics were calculated to estimate gender differences in probability of initiating the target behaviors of tobacco, alcohol, and drug use and sexual intercourse by a given age. This analysis is based on a nonparametric statistic and is thus not bound to assumptions regarding the normality of the data. In addition, it accounts for "censoring" in the data, which in this study refers to students who denied ever having engaged in the respective 
Table II. HIV/AIDS Knowledge

\begin{tabular}{|c|c|}
\hline Area of knowledge & $\begin{array}{l}\text { Percent correct } \\
\text { responses }\end{array}$ \\
\hline \multicolumn{2}{|l|}{ Sexual activity } \\
\hline $\begin{array}{l}\text { One can get AIDS when not using condoms } \\
\text { during sex }\end{array}$ & 91 \\
\hline $\begin{array}{l}\text { If you have AIDS, you can infect your partner } \\
\text { during sex }\end{array}$ & 91 \\
\hline $\begin{array}{l}\text { You can reduce the chances of infection if you } \\
\text { remain abstinent }\end{array}$ & 76 \\
\hline \multicolumn{2}{|l|}{ Intravenous transmission } \\
\hline $\begin{array}{l}\text { One can get AIDS when sharing needles to } \\
\text { inject drugs }\end{array}$ & 78 \\
\hline $\begin{array}{l}\text { One can reduce chances of infection by not } \\
\text { having sex with an injecting drug user }\end{array}$ & 49 \\
\hline $\begin{array}{l}\text { One can get infected during a blood test even } \\
\text { when using sterile instruments }\end{array}$ & 32 \\
\hline \multicolumn{2}{|l|}{ Myths about HIV/AIDS transmission } \\
\hline Can get AIDS by using public toilets & 44 \\
\hline $\begin{array}{l}\text { Can get AIDS by holding hands with an } \\
\text { infected individual }\end{array}$ & 70 \\
\hline Only homosexuals can get AIDS & 30 \\
\hline One can get AIDS through a mosquito bite & 32 \\
\hline There is a cure for AIDS & 41 \\
\hline \multicolumn{2}{|l|}{ Women } \\
\hline $\begin{array}{l}\text { An infected pregnant woman can infect } \\
\text { her baby }\end{array}$ & 67 \\
\hline
\end{tabular}

behaviors. Table III displays the results from these analyses in addition to log rank statistics, which speak to statistically significant gender differences in initiation ages for the target behaviors. Illicit drug use age of initiation and relevant statistics is also reported for males; however, gender differences on this variable were not conducted because only one female admitted to drug use. Table III also contains quartile data, including ages by which $25 \%, 50 \%$, and $75 \%$ of the sample reported having initiated the behaviors of interest.

Based on these analyses, male students, on average, initiated all three of the target behaviors earlier than their female classmates. The mean and median ranges for substance use (including tobacco and alcohol) and sexual activity were similar and approximately in the 14- to 15-year range for males; age of initiation for drug use, however, was slightly higher at approximately 17 years. For females, initiation age statistics were somewhat delayed and approximately within the 15- to 16-year range for substance use and at 17 years for sexual activity. Approximately $50 \%$ of both males and females reported initiation of alcohol use (beyond a few sips) by the age of 16 years. Although 16 years was also the age at which $50 \%$ of the males reported initiating tobacco use and sexual activity, the respective ages for females were 18 and 17 years.

\section{Bivariate and Multivariate Results}

To investigate the association between the risk behaviors addressed in this study, composite indices were created for each of the following target behaviors: tobacco use, alcohol use, and sexual activity. The tobacco use index was based on (1) age of initiation ( 0 points for noninitiators and 1-7 points for initiators depending on their coded age of initiation recoded to provide an inverse relationship between age of initiation and risk); (2) number of days smoked in the past 30 days ( 0 points for nonsmokers and $1-6$ points for smokers depending on the coded time period, in days); and (3) number of cigarettes smoked per day for each day smoked in the last 30 days ( 0 points for nonsmokers and $1-6$ points for smokers depending on the coded number of cigarettes smoked per day in the last month). Higher scores were associated with increased risk for the latter two items. The sum of these scores was used as a tobacco risk composite $(\bar{x}=5.2$, $S D=5.8$, range $=0-19, N=367)$. A reliability analysis of this composite using Cronbach's alpha revealed a strong interitem correlation: $\alpha=.83$.

The alcohol use index was based on the same first two items as the tobacco index; however, the third item was replaced by number of binge drinking episodes in the last 30 days (0 points for non-binge drinkers and 1-6 points for binge drinkers depending on the coded number of binge-drinking episodes in the past month). The scores from each of the items were summed and used as an alcohol risk composite $(\bar{x}=5.2, S D=4.2$, range $=0-21, N=399)$. A reliability analysis of this composite using Cronbach's alpha demonstrated a strong interitem correlation: $\alpha=.83$.

The sexual behavior index included (1) history of sexual intercourse ( 0 points if no history and 1 point for an affirmative response); (2) age of initiation $(0$ points for noninitiators and $1-11$ points for initiators depending on their coded reported age of initiation recoded to provide an inverse relationship between age of initiation and risk); (3) number of lifetime partners (0-50); (4) frequency of condom use ( 0 points for noninitiators and $1-4$ points for initiators depending on the following response choices: almost always, often, sometimes, and never); and (5) casual sexual contact defined by the length of time typically taken to know partner prior to engaging in sexual intercourse $(0$ points for noninitiators and $1-3$ points 
Table III. Kaplan-Meier Survival Functions for Age of Initiation of Target Behavior

\begin{tabular}{|c|c|c|c|c|}
\hline & \multirow[b]{2}{*}{ Survival statistic $^{a}$} & \multicolumn{3}{|c|}{ Percentiles $^{b}$} \\
\hline & & $25 \%$ & $50 \%$ & $75 \%$ \\
\hline \multicolumn{5}{|l|}{ Tobacco use ${ }^{c}$} \\
\hline Males $(N=212, C=49)$ & $\begin{array}{l}14.5(.2), 14.0-15.0 \\
15.5(.2), 15.1-15.9\end{array}$ & $18(.1)$ & $16(.2)$ & $14(.8)$ \\
\hline Females $(N=174, C=119)$ & $\begin{array}{l}16.3(.4), 15.6-17.0 \\
17.5(.2), 17.1-17.9 \\
\text { Log rank } 18.23, d f\end{array}$ & $\begin{array}{l}18(.2) \\
p<.001\end{array}$ & $18(.2)$ & $16(.6)$ \\
\hline \multicolumn{5}{|l|}{ Alcohol use $\mathrm{e}^{d}$} \\
\hline Males $(N=215, C=29)$ & $\begin{array}{l}14.4(.2), 14.0-14.8 \\
15.5(.1), 15.2-15.8\end{array}$ & $16(.1)$ & $16(.1)$ & $14(.4)$ \\
\hline Females $(N=118, C=110)$ & $\begin{array}{l}15.1(.3), 14.5-15.7 \\
15.5(.3), 14.9-16.1 \\
\text { Log rank } 6.61, d f=\end{array}$ & $\begin{array}{l}18(.1) \\
p=.010\end{array}$ & $16(.3)$ & $14(.4)$ \\
\hline \multicolumn{5}{|l|}{ Sexual activity } \\
\hline Males $(N=209, C=48)$ & $\begin{array}{l}15.2(.3), 14.7-15.7 \\
16.0(.1), 15.7-16.3\end{array}$ & $17(.1)$ & $16(.1)$ & $15(.2)$ \\
\hline Females $(N=189, C=175)$ & $\begin{array}{l}17.2(.5), 16.2-18.1 \\
17.0(.3), 16.4-17.6 \\
\text { Log rank } 9.8, d f=\end{array}$ & $\begin{array}{l}18(.6) \\
=.002\end{array}$ & $17(.3)$ & $17(.3)$ \\
\hline \multicolumn{5}{|l|}{ Drug use } \\
\hline Males $(N=198, C=177)$ & $\begin{array}{l}16.7(.5), 15.8-17.6 \\
17.5(.3), 16.9-18.1\end{array}$ & $18(.3)$ & $18(.3)$ & $15(1.5)$ \\
\hline Females $\left(\mathrm{N} / \mathrm{A}^{e}\right)$ & - & & - & \\
\hline
\end{tabular}

${ }^{a}$ Means (first row) and medians (second row) for each gender (standard deviations in parentheses; $95 \%$ confidence interval range).

${ }^{b}$ Percentiles for "survival" (not having initiated the target behavior) by age indicated (standard errors in parentheses).

${ }^{c} C$, Number censored.

${ }^{d}$ Including more than a few sips.

${ }^{e}$ Not available; only one female admitted to a history of drug use.

for initiators depending on the following response choices: more than 6 months, a few months, and a few days). The scores from each of the items were summed and used as a sexual behavior risk composite $(\bar{x}=7.3$, $S D=11.7$, range $=0-68, N=307)$. A reliability analysis of this composite using Cronbach's alpha revealed a strong interitem correlation: $\alpha=.87$. In addition, dropping any of the items for each of the three indices did not improve the reported reliability statistics.

Because the composite risk indices for the three target behaviors were nonnormally distributed and because the summed item responses were composed of ordinal data, nonparametric statistics were used in the following analysis. Spearman correlations were calculated among each of the three risk indices (i.e., tobacco and alcohol use and sexual activity) and the HIV/AIDS knowledge scale total score. Statistically significant $(p<.01)$ correlations were derived between the tobacco, alcohol, and sexual activity risk indices; HIV/AIDS knowledge, however, was not correlated with any of the three composites. A second set of correlations was run on the risk indices based only on students who reported a past history of all three behaviors. Although the correlation coefficients were smaller, tobacco and alcohol use and sexual activity were still significantly $(p<.01)$ correlated; HIV/AIDS knowledge was not correlated with any of the behaviors (see Table IV).

In order to determine the relationship between age of initiation of a particular behavior and its current frequency, four additional Spearman correlations were run. For these analyses, only students who reported a prior history of that behavior were included. The results indicated no association between age of tobacco initiation and frequency of tobacco use within the last 30 days $(r=.006, p=\mathrm{ns}, N=217)$. However, significant correlations were found between age of initiation for alcohol and drug use and current (last 30 days) frequency of these behaviors; age and number of days drank in past month: $r=-.176, p=.005$, $N=261$; age and number of times binge drank (five or more drinks in one sitting) in past month: $r=-.174$, $p=.000, N=260$; age and number of days used drugs in past month: $r=-.789, p=.000, N=22$. 
Table IV. Relationship Among the Risk Behavior Indices and HIV/AIDS Knowledge ${ }^{a}$

\begin{tabular}{|c|c|c|c|c|}
\hline & Tobacco use & Alcohol use & Sexual activity & AIDS knowledge \\
\hline Tobacco use & - & & & \\
\hline Alcohol use & $\begin{array}{l}.60^{*}(n=355) \\
.34^{*}(n=123)\end{array}$ & - & & \\
\hline Sexual activity & $\begin{array}{l}.56^{*}(n=276) \\
.39^{*}(n=75)\end{array}$ & $\begin{array}{l}.51^{*}(n=299) \\
.39 *(n=74)\end{array}$ & - & \\
\hline AIDS knowledge & $\begin{array}{l}.03(n=309) \\
.08(n=101)\end{array}$ & $\begin{array}{l}.05(n=339) \\
.06(n=103)\end{array}$ & $\begin{array}{l}-.04(n=280) \\
-.05(n=63)\end{array}$ & - \\
\hline
\end{tabular}

Furthermore, the age of initiation for sexual activity was significantly associated with lifetime number of partners: $r=-.465, p=.000, N=164$. Except for tobacco use, early initiation of the rest of the target behaviors is significantly associated with increased frequency in current use (for substances) and higher number of lifetime partners (for sexual activity).

In addition to bivariate analyses, three binary logistic regressions were modeled to predict sexual behavior risk. Although some of the predictor variables were ordinal in nature, they were treated as interval and included in the regression models because they were based on a continuous underlying construct and had several response options (between seven and nine). Assuming that continuous quantitative attributes and multiple response options are present, it is relatively common practice to safely assume ordinal data as interval in multivariate models (Tabachnick and Fidell, 2001) because Type I and Type II errors are not dramatically affected (Jaccard and Wan, 1996). The outcome variables used in these analyses included (1) prior history of sexual intercourse (no vs. yes), (2) number of lifetime sexual partners ( $<4$ vs. $\geq 4)$, and (3) frequency of condom use (never/sometimes vs. often/always). The predictor variables for prior history of sexual intercourse included gender, age, current (last 30 days) use of tobacco and alcohol, current binge drinking, and age of initiation for tobacco, alcohol, and drug use. In addition to all of these variables, age of sex initiation was used to predict lifetime number of sexual partners. Finally, the predictors used to model frequency of condom use were gender, age, current alcohol use and binge drinking, casual sex (defined by length of time taken to know partner before engaging in sexual intercourse), number of lifetime partners, age of sex initiation, intention to use condoms (based on response, strongly disagree to strongly agree, on a 5-point Likert scale regarding intention to use condoms during next sexual intercourse), and HIV/AIDS knowledge total score.

When predicting past sexual history, gender and current age were covaried in the regression equation. Resulting statistics indicated that $84 \%$ of the respondents were correctly identified by these two variables alone as being sexually experienced or inexperienced (goodness of fit $=333.5$; Nagelkerke $R^{2}=.60 ;-2 \log$ likelihood $\left.=271.7\right)$. The variables used in this model significantly predicted group membership (model $\chi^{2}=194.5, d f=2, p<.001$ ). With the addition of the remaining predictor variables in the model, the percentage of correctly identified respondents did not change; however, the fit indices improved slightly (goodness of fit $=293.9$; Nagelkerke $R^{2}=.60 ;-2 \log$ likelihood = 247.4). Again, the final model significantly predicted group membership (model $\left.\chi^{2}=218.8, d f=9, p<.001\right)$. Based on odds ratios $(\mathrm{OR})$ resulting from this model, female students were less likely $(\mathrm{OR}=0.04)$ and older students were more likely $(\mathrm{OR}=1.50)$ to be sexually experienced than male and younger students, respectively. In addition, although not statistically significant, younger age of alcohol initiation $(\mathrm{OR}=0.85)$ and greater frequency of alcohol $(\mathrm{OR}=1.5)$ and drug $(\mathrm{OR}=54.0)$ use within the last 30 days were associated with a higher likelihood of past sexual history. Although the insignificant $p$ value specifically in the case of the drug use variable may be due to a small proportion of the sample engaging in this behavior, the extreme odds ratio statistic may also be a by-product of small cell sizes. The relationship between current drug use and sexual experience was clarified using a crosstab table; all nine students who admitted to drug use in the last month were also sexually experienced.

Among sexually active students only, gender and current age were covaried in a binary regression equation when predicting lifetime number of sexual 
partners. Together, these two variables correctly identified $67 \%$ of the respondents (goodness of fit $=145.2$; Nagelkerke $R^{2}=.16 ;-2 \log$ likelihood $=171.8$ ). The variables included in this model significantly predicted membership into either the $<4$ or $>4$ lifetime number of sexual partners group (model $\chi^{2}=17.6, d f=2, p<.001$ ). With the addition of the rest of the predictor variables, the percentage of correctly identified respondents improved by $8 \%$ (a total of $75 \%$ ) (goodness of fit $=$ 138.3; Nagelkerke $R^{2}=.38 ;-2 \log$ likelihood $=$ 142.9). Again, the variables in the model significantly predicted group membership (model $\chi^{2}=46.6, d f=$ $10, p<.001$ ). Much like the sexual history model, the odds ratios resulting from the final model suggested that female students were less likely $(\mathrm{OR}=0.11)$ and older students were more likely $(\mathrm{OR}=1.8)$ to have four or more lifetime sexual partners than male and younger students. In addition, early age of initiation of tobacco use and sexual activity were associated with greater likelihood of having four or more lifetime sexual partners, with ORs of 0.79 and 0.58 , respectively.

Using a binary logistic regression, we modeled frequency of condom use among sexually active students. The percentage of respondents that were correctly identified was 78 (goodness of fit $=132.2$; Nagelkerke $R^{2}=.37 ;-2 \log$ likelihood $=72.7$ ). The model significantly predicted group membership between students who never/sometimes and often/always use condoms during sexual intercourse (model $\chi^{2}=24.6, d f=9, p=.003$ ). The odds ratios resulting from the final model suggested that sexually active female students were more likely than male students $(\mathrm{OR}=6.58)$ to use condoms inconsistently (sometimes or never) during sexual intercourse. In addition, early initiation of sexual behavior $(\mathrm{OR}=$ $0.66)$ and older age $(\mathrm{OR}=0.43)$ were associated with inconsistent condom use. Conversely, students were more likely to use condoms consistently (always or often) if they admitted having the intention to use condoms during their next sexual encounter, as determined on a 5-point Likert type scale $(\mathrm{OR}=$ 0.57). Also notable was the insignificant relationship between HIV/AIDS knowledge and frequency of condom use. Table V contains the results from the three regression analyses.

\section{DISCUSSION}

\section{Conclusions}

The weak economy and unstable political circumstances in Armenia contribute to its increased vulnerability to a nationwide HIV/AIDS epidemic. For several key reasons, including liberalization of sexual behavior, postponement of marriage, military conflict, and an increase in prostitution, substance use, and sexually transmitted infections, the general population in Armenia, but especially young adults, are at risk for contracting and spreading the virus (UNAIDS/WHO, 2002).

\section{Prevalence of Health-Risk Behaviors}

Unlike most other Eastern block countries, drug use among the student population in this study was not significant; only $6 \%$ of the respondents indicated having used drugs in the past, with an average initiation age of approximately 17 years. However, a history of tobacco use ( $84 \%$ of males and $48 \%$ of females) and alcohol use ( $89 \%$ of males and $67 \%$ of females) was relatively common in this sample of students, with an average initiation age of 14 and 16 years, respectively. Of those who indicated having tried tobacco and alcohol, a significant proportion, particularly of the male respondents, reported high frequencies of use. This was true for both the number of days they engaged in the behavior in the last month and the number of times they engaged in the behavior on a given day within the last month. In addition, significant gender differences were noted with regard to the initiation of tobacco and alcohol, suggesting that in general, males engaged in such behaviors earlier than females.

Sexual behaviors were also addressed in this study to determine the level of risk present in the student population. Significant gender differences were found in sexual history, including past history and initiation age of sexual intercourse, as well as number of lifetime sexual partners. Clearly, the males in this sample were at a much higher risk than the females, with a sexual initiation age of 15 years and with $7.3 \mathrm{av}$ erage number of lifetime partners. Of the females who were sexually active (7\%), the average age for sexual initiation was 17 years, with 1.2 average number of lifetime sexual partners. The gender differences found in this sample are unlike those found in similar studies in neighboring countries. For example, a survey of Russian adolescents (ages 15-17 years) indicated that $39 \%$ of the males and $41 \%$ of the females reported having had sexual intercourse (Amirkhanian et al., 2001). Cultural factors in Armenia are thought to partly be responsible for the significant gender gap. Historically, Armenian attitudes regarding sexual mores have been quite conservative and consistent with the familiar male-female double standard 
Table V. Binary Logistic Regression Statistics for Sexual Risk

\begin{tabular}{|c|c|c|c|c|c|c|}
\hline Outcome & Predictor & B & Wald & $p$ & Odds ratio & $95 \% \mathrm{CI}$ \\
\hline \multirow[t]{9}{*}{ Ever had sex ${ }^{a}$} & 1. Gender $(1=\mathrm{M} ; 2=\mathrm{F})$ & -3.21 & 64.40 & .00 & .04 & $.02-.09$ \\
\hline & 2. Current age & .38 & 3.90 & .05 & 1.46 & $1.00-2.12$ \\
\hline & 3. Current tobacco use $\mathrm{e}^{b}$ & .05 & .52 & .47 & 1.60 & $.91-1.22$ \\
\hline & 4. Current alcohol use & .38 & 3.10 & .08 & 1.47 & $.96-2.24$ \\
\hline & 5. Current binge drinking ${ }^{c}$ & -.01 & .00 & .98 & 1.00 & $.67-1.48$ \\
\hline & 6. Current drug use & 3.99 & .09 & .76 & 54.06 & $.00->100$ \\
\hline & 7. Age of tobacco initiation & -.08 & .96 & .33 & .92 & $.78-1.09$ \\
\hline & 8. Age of alcohol initiation & -.16 & 3.44 & .06 & .85 & $.71-1.01$ \\
\hline & 9. Age of drug initiation & .01 & .00 & .97 & 1.00 & $.63-1.63$ \\
\hline \multirow[t]{10}{*}{ Four or more sex partners ${ }^{d, e}$} & 1. Gender & -2.19 & 3.57 & .06 & .11 & $.01-1.10$ \\
\hline & 2. Current age & .56 & 5.18 & .02 & 1.75 & $1.10-2.85$ \\
\hline & 3. Current tobacco use & -.02 & .08 & .77 & .98 & $.83-1.15$ \\
\hline & 4. Current alcohol use & -.07 & .07 & .78 & .93 & $.56-1.56$ \\
\hline & 5. Current binge drinking & .28 & 1.33 & .25 & 1.32 & $.82-2.14$ \\
\hline & 6. Current drug use & -.93 & 1.86 & .17 & .39 & $.10-1.51$ \\
\hline & 7. Age of tobacco initiation & -.24 & 3.92 & .05 & .79 & $.63-1.00$ \\
\hline & 8. Age of alcohol initiation & .15 & 1.23 & .27 & 1.16 & $.89-1.50$ \\
\hline & 9. Age of drug initiation & -.68 & 2.70 & .10 & .51 & $.23-1.14$ \\
\hline & 10. Age of sex initiation & -.54 & 10.34 & .01 & .58 & $.42-.81$ \\
\hline \multirow[t]{9}{*}{ Frequency of condom use $\mathrm{e}^{e, f}$} & 1. Gender & 1.92 & 3.47 & .06 & 6.84 & $.90-51.66$ \\
\hline & 2. Current age & -.85 & 4.37 & .04 & .43 & $.19-.95$ \\
\hline & 3. Current alcohol use & .06 & .02 & .88 & 1.06 & $.52-2.17$ \\
\hline & 4. Current binge drinking & -.45 & 1.70 & .19 & .64 & $.32-1.26$ \\
\hline & 5. Casual sex ${ }^{g}$ & -.48 & 1.38 & .24 & .62 & $.28-1.38$ \\
\hline & 6. Number of partners & -.08 & 1.77 & .18 & .93 & $.82-1.04$ \\
\hline & 7. Age of sex initiation & -.41 & 5.26 & .02 & .66 & $.47-.94$ \\
\hline & 8. Intention to use condoms ${ }^{h}$ & -.56 & 4.75 & .03 & .57 & $.35-.95$ \\
\hline & 9. HIV/AIDS knowledge & -.16 & 2.33 & .13 & .86 & $.70-1.05$ \\
\hline \multirow{2}{*}{\multicolumn{7}{|c|}{ 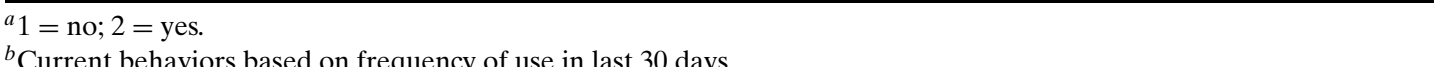 }} \\
\hline & & & & & & \\
\hline \multirow{2}{*}{\multicolumn{7}{|c|}{${ }^{c}$ Binge drinking (five or more drinks in one sitting) in last 30 days. }} \\
\hline & \multicolumn{6}{|c|}{${ }^{d} 1=<4$ partners; $2=\geq 4$ partners. } \\
\hline \multirow{2}{*}{\multicolumn{7}{|c|}{$\begin{array}{l}{ }^{e} \text { Based only on students who reported having had sexual intercourse. } \\
f_{1}=\text { alwavs/often } 2=\text { sometimes/never. }\end{array}$}} \\
\hline & \multicolumn{6}{|c|}{${ }^{f} 1=$ always/often $; 2=$ sometimes $/$ never. } \\
\hline \multicolumn{7}{|c|}{${ }^{g}$ Length of time taken to know partner prior to engaging in sexual intercourse. } \\
\hline $\begin{array}{l}{ }^{h} \text { Based on response (strongly } \\
\text { during next sexual intercours }\end{array}$ & gree to strongly agree) on a $5-\mathrm{p}$ & int Like & & & & \\
\hline
\end{tabular}

(McGoldrick et al., 1982). Part of maintaining honor involved ensuring the "purity" of the women in the family. Women who had "been around" were not considered good marriage material (Bakalian, 1993). Due to the conservative nature of the culture and the traditional male-female double standard with regard to sexuality, it is suspected that some social desirability bias was present in the self-report of sexual behavior histories, with males more likely to overreport and females to underreport. The social desirability suspicion is based on several qualitative observations made during the administration of the surveys; for example, there were instances where male students appeared boastful about the number of sexual partners and asked aloud among their peers how they should report high numbers. Conversely, the females appeared more protective of their responses and expressed concern about anonymity. Such a response bias, however, can only narrow the gap in gender differences but does not close it. Regardless of the exact degree of gender differences, it is evident from the data that they do exist and thus are important to acknowledge. This information is critical for the design of prevention modules because such a gender discrepancy is not typical in samples where intervention programs have been implemented and studied. Because intervention efforts take into consideration the behavioral history of the target population (DiClemente et al., 1996), any observed differences in this sample can help in tailoring a sample-specific program.

In addition to gender differences, important information regarding the students' behavioral patterns was collected. Specifically, frequency of current (last 30 days) substance use, particularly alcohol and drugs, was inversely associated with initiation age, suggesting that the earlier the respondents engaged 
in this behavior, the higher was the current frequency of the behavior. This was true for alcohol and illicit drug use within the last month and lifetime number of sexual partners. In addition, significant predictors of lifetime number of sexual partners $(>4)$ among sexually active students included initiation ages for sexual activity and tobacco use. These results suggest that reaching students before they engage in such behaviors could optimize prevention measures. Therefore, delaying initiation of the target behaviors may serve as a protective factor for later risky behaviors, making this an imperative objective in a prevention module.

\section{HIVIAIDS Knowledge}

The data from this study indicate that knowledge about HIV/AIDS is variable among the students attending higher education institutes in Armenia. Knowledge was notably low with regard to the intravenous risks of HIV transmission and persistent myths. Although accurate knowledge regarding possible routes of transmission is critical for decreasing infection risk, it is also as important to dispel persistent myths (Boyer and Tschann, 1999). Myths such as "AIDS is only a homosexual disease" and "there is a cure for AIDS" misrepresent the risk facing sexually active heterosexuals. For a heterosexual, these myths provide a false sense of security because they lead to the belief that one is not at risk for acquiring HIV. Partial knowledge, therefore, regarding HIV/AIDS can further perpetuate the risk of infection. Furthermore, considering that the student population in this study is among the educated and best-informed groups, one can safely assume that the knowledge base in the general population is even lower.

Consistent with the literature (Boyer and Tschann, 1999; Hingston and Strunin, 1992; Shafer and Boyer, 1991), there was virtually no correlation between the HIV/AIDS knowledge scale scores and students' high-risk sexual behaviors. Likewise, regression results indicated that HIV/AIDS knowledge made an insignificant contribution to the frequency of condom use among sexually experienced students. Prevention programs, therefore, that are geared toward increasing HIV/AIDS/STI knowledge may be successful in doing just that, but they do not necessarily decrease HIV risk, including increasing the frequency of condom use or decreasing rates of sexual intercourse and number of sexual partners. Although important, a knowledge-based intervention model alone is not sufficient to deter risky behavior. In addition to a sound knowledge base, factors that more successfully predict behavior in a particular cultural setting must be identified and measured. Therefore, any HIV/AIDS prevention module for Armenian youth should begin with improving the knowledge base of the target population about HIV/AIDS and its mode of transmission while also taking into account the role of personal beliefs, socialization processes, cultural factors, and societal and peer norms.

\section{Tobacco, Alcohol, and Sexual Activity}

HIV/AIDS risk cannot be studied and addressed in a vacuum. Because there was such a close association between tobacco use, alcohol use, and sexual activity in this sample, it is imperative that the contribution of each to an increased risk for contracting HIV/STIs be acknowledged. Likewise, the regression analyses modeling sexual history suggested an association between it and frequency of alcohol and drug use within the last month. When under the influence of drugs or alcohol, individuals are more likely to engage in unplanned, and thus riskier, activities. In addition, they may experience impaired judgment and have decreased social inhibitions, placing them at greater risk for engaging in riskier sexual activity, including unprotected sex. In one study, alcohol and drug use explained $10 \%$ of the variance in sexual risk; not only were these adolescents more sexually experienced, they were also more likely to engage in riskier sex (Boyer and Tschann, 1999).

Although the link between alcohol and drug use with risky sexual behavior is significant in the literature (Keller et al., 1991; Mott and Haurin, 1998; Rosenbaum and Kandel, 1990; Shafer and Boyer, 1991), relatively few studies have looked at the association between tobacco use and sexual behavior. An early age of sexual initiation is often associated with not only alcohol use but also tobacco use (Brown et al., 1992). In addition, regular smoking has been associated with higher frequencies of deviance, including lifetime drug use and dependence (Bonard et al., 2001; Lewinsohn et al., 2000). Therefore, although tobacco and alcohol use are not direct risks for HIV transmission, they have collectively been regarded as "problem behaviors" (Costa et al., 1999; Turbin et al., 2000) associated with HIV risk. The results from this study suggest that in addition to demographic variables, substance use and the students' age of initiation were significant predictors of sexual risk-taking behaviors, including a history of sexual intercourse, 
number of lifetime partners, and frequency of condom use. Because of this association and because tobacco and alcohol use were found to be relatively prevalent in males and females in this sample, prevention measures that target the delay or decrease in frequency of these behaviors may provide a successful strategy to reducing HIV sexual risk behaviors.

\section{Study Limitations}

Although efforts were made to sample as diverse a student population as possible within the constraints of limited resources, the use of a nonrandom convenience sample may limit the generalizability of the results from this study. It is also important to note that the analyses are based only on second- and third-year students from the sampled schools. In addition, students in the higher education institutes represent anywhere from one-third to one-half of all secondary school graduates in Armenia. A majority of youth do not pursue higher education after secondary schooling (R. Gasparyan, Minister of Education, Yerevan Armenia, Personal Communication, 2000). Instead, the males may pursue employment, including travel to neighboring countries, or join the military, and the females often pursue marriage. Because virtually no data are available on the behaviors of this population, it is not clear whether the level of risk based on the data gathered in this study is an over- or underestimation of the risk present in the nonstudent population. Finally, the apparent social desirability bias, specifically in students' responses to the sexual activity items, is a considerable potential limitation. The results, therefore, regarding history of sexual activity should be interpreted with this possibility in mind.

\section{Future Directions}

The results from this study demonstrate that there is a pressing need for HIV/AIDS prevention for youth in Armenia. Schools can be good targets for such an intervention because (1) in general and as indicated by the results of this study, AIDS is a problem of young adults in Armenia, (2) schools provide easy access to young people and a relatively efficient forum for communicating pro-health messages, (3) young people are most likely to benefit from behavioral interventions because their behaviors and attitudes are less solidified, and (4) young people have the most potential to be influenced by others, including peers and the media. In Armenia, students are required by law to attend school until the age of 14 years. Most students, however, stay in school and finish high school at the age of 16 years. Because most students reported initiation of risk behaviors between the ages of 14 and 16 years, it is important that any school-based prevention measures be implemented for students prior their engagement in these behaviors. For this reason, it is recommended that school-based interventions be implemented in the seventh grade (age 12 years). Finally, the results from this study strongly suggest the importance of early intervention designed to delay the initiation of risk behaviors as a means for decreasing HIV/AIDS risk.

A few descriptive attempts have been made to introduce students in Armenia to an HIV/AIDS/STI education program through the school system. In 1997, medical students in Armenia initiated such a program for approximately 3,000 students (grades $8-10$ ). Whereas $40 \%$ of the teachers showed opposition to the implementation of the program, $97 \%$ of the students reported that this kind of information would be beneficial for their health and well-being. Furthermore, the authors reported that $67 \%$ of the adolescents knew very little about the etiology, transmission, and consequences of HIV/AIDS (TerHoyakimyan et al., 1998). Although the roots of the teachers' opposition to such programs are unclear and beyond the scope of this study, it may be speculated that teachers are unaware of the need for HIV/STI prevention programs (i.e., unaware of the extent to which school-age children are engaging in "risky" behaviors), are afraid of the implications of such programs in terms of whether and to what extent they will promote risky behaviors, and are perhaps unaccepting of the existence of the problem (i.e., HIV/AIDS) in their country and specifically in their communities. Although overcoming such attitudes can be a relatively difficult task, the process can be started by first educating teachers regarding the presence and extent of the existing problem and by implementing a topdown approach of a "universal" program monitored by the national Ministry of Education or by local school boards. With regard to the surveys administered to gather data for this study, officials from the Ministry of Education, the deans and professors from the educational institutes, and especially the students were in general very open to the possibility of a school-based intervention model. An overwhelming majority of the participants reported positive opinions about the objectives of the study. They indicated that their participation in this survey was an educational 
experience in and of itself and that an HIV/AIDS intervention has long been due for their peers.

\section{Concluding Remarks}

Although the economic and political instability in Armenia following its recent independence from the former Soviet Union have contributed to the current threat of an HIV/AIDS epidemic, it is crucial to realize that changes in the political structure also serve to provide an infrastructure supporting prevention and/or intervention measures. The mass media, the most likely source of HIV/AIDS information as endorsed by the students in this study, and local and/or international nongovernmental organizations can have a significant role in communicating pro-health messages, both to the public at large and in various institutional settings such as schools and in the military. This study shows it would be important to do so.

\section{ACKNOWLEDGMENTS}

This project was conducted in collaboration with the American University of Armenia's (AUA) Center for Health Sciences Research (CHSR) and was largely funded by Development Support for Armenia (DSA). Special thanks go to Dr. Anahid Demirchyan of AUA for managing the project and the CHSR staff for managing data entry.

\section{REFERENCES}

Amirkhanian, Y. A., Dennia, V., and Kelly, J. A. (2001). Risk factors for HIV and other sexually transmitted diseases among adolescents in St. Petersburg, Russia. Family Planning Perspectives, 33, 106-112.

Atovmyan, M. (2001). Issues of prostitution and trafficking of women in Armenia (United Nations Development Program Gender Studies Report.) Retrieved on May 1, 2001 from http://www.undp.am/archive/gender/Studies/MGGS/3.htm.

Bakalian, A. (1993). Armenian-Americans: From being to feeling Armenian. New Brunswick, NJ: Transaction.

Bonard, L., Janin-Jacquat, B., and Michaud, P. (2001). Who are the adolescents who stop smoking? European Journal of Pediatrics, 160, 430-435.

Boyer, C. B., and Tschann, J. M. (1999). Predictors of risk for sexually transmitted disease in ninth grade urban high school students. Journal of Adolescent Research, 14, 448-466.

Brown, L. K., DiClemente, R. J., and Beausoleil, N. I. (1992). Comparison of human immunodeficiency virus related knowledge, attitudes, intentions, and behaviors among sexually active and absent young adolescents. Journal of Adolescent Health, 13, $140-145$.

Carasso, M. J. (1998). Renegotiating HIV/AIDS prevention for adolescents. Issues in Comprehensive Pediatric Nursing, 21, 203-261.
Centers for Disease Control and Prevention. (2003). Youth risk behavioral surveillance system. Available at www.cdc.gov/yrbss.

Costa, F. M., Jessor, R., and Turbin, M. S. (1999). Transition into adolescent problem drinking: The role of psychosocial risk and protective factors. Journal of Studies on Alcohol, 60, 480-490.

DiClemente, R. J., Brown, L. K., Beausoleil, N. I., and Lodico, M. (1993). Comparison of AIDS knowledge and HIV-related sexual risk behaviors among adolescents in low and high AIDS prevalence communities. Journal of Adolescent Health, 14, 231-236.

DiClemente, R. J., Hansen, W. B., and Ponton, L. E. (Eds.). (1996). Handbook of adolescent health risk behavior. New York: Plenum.

Hakobian, J. (2001). AIDS in Armenia: Experts battle ignorance and apathy. Armenia Week, 2001 (December 7). Available at www.armeniaweek.com/dec072001/aids.html.

Harutyunyan, T., Ghukasyan, G., Chilingaryan, G., Hovhannisyan, L., Manukyan, R., and Petrosyan, V. (1998). The problem of sexually transmitted diseases in Armenia. Yerevan: Armenia: American University of Armenia. Public Health Department.

Henshaw, S. K., Singh S., and Haas, T. (1999). The incidence of abortion worldwide. International Family Planning Perspectives, 25 (Supplement), S30-S388.

Hingson, R. W., and Strunin, L. (1992). Monitoring adolescents' response to the AIDS epidemic: Changes in knowledge, attitudes, beliefs, and behaviors. In R. J. DiClemente (Ed.), Adolescents and AIDS: A generation in jeopardy (pp. 17-33). Newbury Park, CA: Sage.

Hochhauser, M. (1989). AIDS and chemical dependency: Prevention needs of adolescents. Journal of Psychoactive Drugs, 21, 381-385.

International Center for Alcohol Policies (2002). Drinking age limits. Retrieved on July 24, 2002 from http://www.oicap. org/publications/report4.html.

Jaccard, J., and Wan, C. K. (1996). LISREL approaches to interaction effects in multiple regression. Thousand Oaks, CA: Sage.

Keller, S. E., Bartlett, J. A., Schleifer, S. J., Johnson, R. L., Pinner, E., and Delaney, B. (1991). HIV-related sexual behavior among a healthy inner-city heterosexual adolescent population in an endemic area of HIV. Journal of Adolescent Health, 12, $44-48$.

Lewinsohn, P. M., Brown, R. A., Seeley, J. R., and Ramsey, S. E. (2000). Psychosocial correlates of cigarette smoking abstinence, experimentation, persistence and frequency during adolescents. Nicotine and Tobacco Research, 2, 121-131.

Markosyan, K. (2000). Substance use prevention school project: Development, implementation, and evaluation. Executive summary. Yerevan, Armenia: American University of Armenia, Center for Health Sciences Research.

McGoldrick, M., Pearce, J. K., and Giordano, J. (Eds.). (1982). Ethnicity and family therapy. New York: Guilford.

Melikyan, G. L. (1999). HIV infection among commercial sex workers in Yerevan: Findings and policy recommendations. Armenian Forum: A Journal of Contemporary Affairs, 2, 1-16.

Ministry of Health. (2000, September). Spread of HIV infection in Armenia. Yerevan, Armenia: National Center for AIDS.

Mott, F. L., and Haurin, R. J. (1988). Linkages between sexual activity and alcohol and drug use among American adolescents. Family Planning Perspectives, 20, 128-136.

Nagy, S., Hunt, B., and Adcock, A. (1990). A comparison of AIDS and STD knowledge between sexually active alcohol consumers and abstainers. Journal of School Health, 60, 276279.

National Tobacco Control Program. (2002). Law of the Republic of Armenia on Tobacco Control (Draft). Retrieved on July 24 2002 from http://tobaccocontrol.am/lw-tc(draft).html.

Rosenbaum, E., and Kandel, D. B. (1990). Early onset of adolescent sexual behavior and drug involvement. Journal of Marriage and the Family, 52, 783-798. 
Shafer, M., and Boyer, C. B. (1991). Psychosocial and behavioral factors associated with risk of sexually transmitted diseases, including immunodeficiency virus infection, among urban high school students. Journal of Pediatrics, 199, 826833.

Soros Foundation Network. (2002). The crisis: Rising drug use and HIV in Eastern Europe. Retrieved on July 22, 2002 from www. soros.org/harm-reduction/resourceguide/text/IHRD3.html.

Stinson, F. S., and DeBakey, S. F. (1993). Prevalence of alcohol problems among selected AIDS groups: United States, 1988. Addiction, 88, 1139-1147.

Tabachnick, B. G., and Fidell, L. S. (2001). Using multivariate statistics, 4th Ed. Boston: Allyn and Bacon.

Ter-Hoyakimyan, A., Sargsyan, D. A., Topchyan, S. G., Zohrabyan, L. S., and Ghoukasyan, G. (1998, June/July). Peculiarities of anti-AIDS program aimed at teenagers in Armenia. Paper presented at the International Conference on AIDS, Geneva.

Turbin, M. S., Jessor, R., and Costa, F. M. (2000). Adolescent cigarette smoking: Health-related behavior or normative transgression? Prevention Science, 1, 115124.
UNAIDS. (1998). Joint United Nations Programme on HIV/AIDS, Statement by the executive director. Retrieved on February 24, 2000 from http://www.unaids.org.

UNAIDS. (1999). AIDS not losing momentum, HIV has infected 50 million, killed 16 million, since epidemic began. Retrieved on January 28, 2000 from www.UNAIDS.org/whatsnew/ press/eng/london231199.html.

UNAIDS/WHO. (1998). Report on the global HIV/AIDS epidemic-The evolving picture region by region. Retrieved on April 22, 2003 from http://www.unaids.org/hivaidsinfo/ statistics/june98/global_report/rep_html/report3.html.

UNAIDS/WHO. (2000). Epidemiological fact sheet on HIV/AIDS and sexually transmitted infections, Armenia, 2000 update. Retrieved on September 5, 2000 from http://www.unaids.org/ hivaidsinfo/statistics/june00/fact_sheets/pdfs/armenia.pdf.

UNAIDS/WHO. (2002). Epidemiological fact sheet on HIV/AIDS and sexually transmitted infections, Armenia, 2002 update. Retrieved on July 24, 2002, from http://www. unaids.org/ hivaidsinfo/statistics/fact_sheets/pdfs/Armenia_en.pdf.

World Health Organization. (1997). Tobacco or health: A global status report. Retrieved on July 24, 2002 from http://www. who.org/programmes/psa/toh.htm. 